\title{
Improved estimation of nitrogen uptake in grasslands using the nitrogen dilution curve (Reyes et al. 2015), 35:1561-1570
}

\author{
Gilles Lemaire $^{1} \cdot$ François Gastal $^{1}$
}

Published online: 5 September 2016

(C) INRA and Springer-Verlag France 2016

The recent paper published by Reyes et al. in Agronomy for Sustainable Development (vol 35: 1561-1570) is based on the use of the nitrogen dilution curves which we have developed the theory and the practical use for $\mathrm{N}$ status diagnostic in crops (see, Lemaire and Gastal 1997; Lemaire et al. 2008; Gastal et al. 2014) for estimation of nitrogen uptake, and then nitrogen balance from grasslands subjected to different fertilizer and cutting regimes. This objective is very relevant, and the use of a large data base issued from series of experiments in a large range of conditions appears very interesting for testing the robustness of the method. Nevertheless, despite of its high interest, this paper suffers of large misinterpretation of the basic principles and methodology of $\mathrm{N}$ dilution curves. The objective of the paper being to demonstrate that previous stage of defoliation (or frequency) should modify the critical $\mathrm{N} \mathrm{di-}$ lution curve of a natural grassland; it is then very important that determination of these "critical" curves would be realized in perfect agreement with the theory:

1- The dilution of $\mathrm{N}$ in crops is a process driven by crop growth relating crop growth rate $(\mathrm{dW} / \mathrm{dt})$, if $\mathrm{W}$ is crop mass, with crop $\mathrm{N}$ uptake rate $(\mathrm{dN} / \mathrm{dt})$. The allometric form of the relationship $N=\mathrm{aW}^{1-b}$ (or $\% N=\mathrm{aW}^{-b}$ that is the "dilution curve) implies a constant proportionality between the relative $\mathrm{N}$ uptake rate $(\mathrm{dN} / \mathrm{Ndt})$ and the relative crop growth rate $(\mathrm{dW} / \mathrm{Wdt})$, that corresponds to coefficient 1-b. So, determination of an $\mathrm{N}$ dilution curve

Gilles Lemaire

gilles.lemaire.inra@gmail.com

François Gastal

francois.gastal@lusignan.inra.fr

1 INRA, 86600 Lusignan, France requires sequential determinations of both $\mathrm{W}$ and $\mathrm{N}$ (or $\% N$ ) during a growth process, i.e., here for grasslands, from beginning of regrowth after the preceding cut (harvest) until the following cut (harvest). Once the reference $\mathrm{N}$ dilution curve (critical) is established in dynamic term, then it is possible to use it for diagnosis of crop $\mathrm{N}$ status by using static $\mathrm{N}, \mathrm{W}$ data points.

2- As stated by authors cited above, the $\mathrm{N}$ dilution is a monotonic process with a constant value of " $b$ " during all the vegetative growth period of crops when plants are elaborating only leaves and stems. After onset of flowering, leaf senescence occurs, and then $\mathrm{N}$ accumulation in biomass is the result of different processes: continuing $\mathrm{N}$ absorption, $\mathrm{N}$ recycling, and $\mathrm{N}$ losses leading in general to a drop in coefficient " $b$ " (acceleration of $\mathrm{N}$ dilution). It is the reason why for all crops it has been highly recommended to limit the use of "critical" $\mathrm{N}$ dilution curves to the period before flowering.

3- So, for testing the first hypothesis of this paper, are grasslands subjected to different cutting regimes follow or not the same $\mathrm{N}$ dilution curve? It should have been necessary to follow the dynamic of regrowth of different grasslands after different previous cutting regimes and then to establish whether previous cutting treatments would have or not affected the N-W dynamics.

4- By using only the static N-W data obtained at each harvest, the method used in this paper confounded the effect of previous cutting regime with the effect of stage of harvest. The four cut treatments were always harvested earlier than the three or two cut treatments. The $\mathrm{N}$ dilution is monotonic (constant value of $b$ ) as long as plant is growing (leaf and stem production), but when crop mass approach its maximum, because of accumulation of leaf senescence, then the value of $b$ drop. It is the reason why the dilution curves of Fig. 3 for three and two cut 
treatments are under the Lemaire reference and the four cut treatment one. This difference can be explained by the fact that treatments with two and three cuts corresponded in general to very late harvest where leaf senescence processes dominated the N-W rela- tionships. So, this difference may be not due to a shift in plant population or plant morphophysiology linked to previous cutting regime, but may be only the consequence of late harvest beyond the validity domain of $\mathrm{N}$ dilution theory.

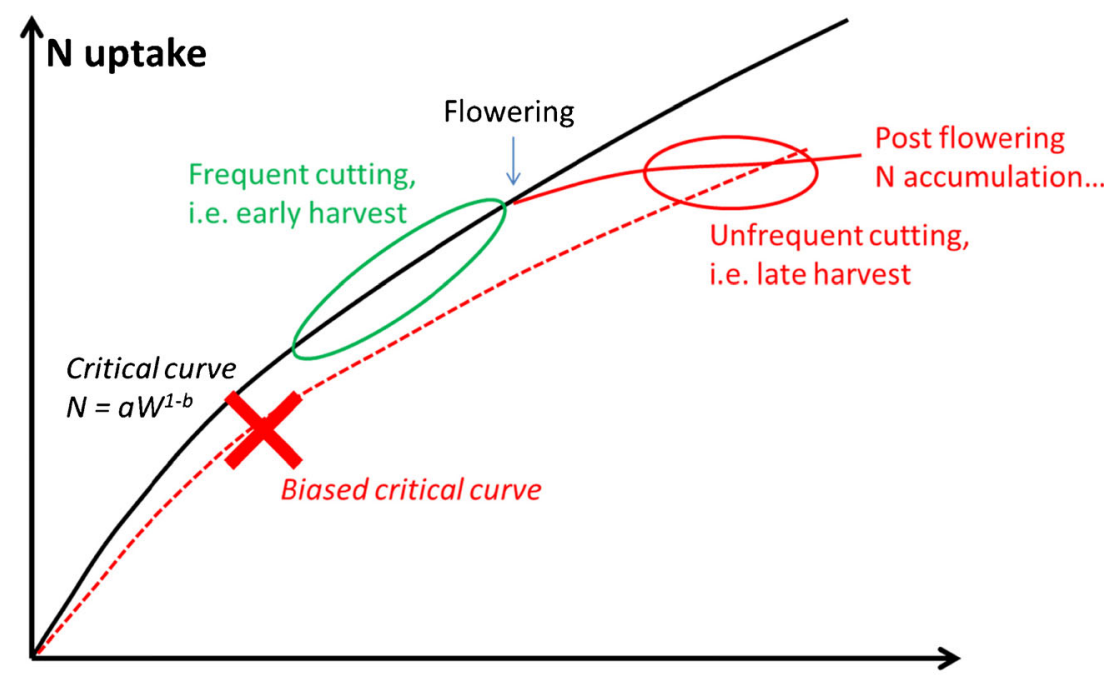

W-Biomass

So, in the conclusion of this paper, there is a confounding between an expected effect of frequency of defoliation on "critical N dilution curve," i.e., as a consequence of a physiological or genetical shift in plant $\mathrm{N}$ uptake capacity? And a trivial effect of late harvest that can be interpreted as a consequence of post-flowering leaf senescence and $\mathrm{N}$ recycling processes that are out of the scope of the $\mathrm{N}$ dilution theory.

We think that this misinterpretation of the results of this paper must be underlined because it could suggest a huge variability of critical $\mathrm{N}$ dilution curves according to context despite the evidence that these critical curves are very stables across crop species, climatic, and soil conditions (Gastal et al. 2014) and even for complex natural vegetation (Duru et al., 1997). It is clear that frequently cut meadow by removing low quantity of biomass (W) at each harvest are removing higher quantity of $\mathrm{N}$ per year and per unit of produced biomass than unfrequently harvested ones. This fact is only due to the nonlinearity between growth rate $\mathrm{dW} / \mathrm{dt}$ and $\mathrm{N}$ uptake rate $\mathrm{dN} / \mathrm{dt}$ during regrowth process and not to a physiological or genetical shift of plant $\mathrm{N}$ uptake capacity in response to defoliation frequency.

\section{References}

Duru M, Lemaire G, Cruz P (1997) The nitrogen requirement of major agricultural crops: grasslands. In: Lemaire G (ed) Diagnosis on the nitrogen status in crops. Springer-Verlag, Heidelberg (Allemagne), pp 59-72

Gastal F, Lemaire G, Louarn G, Durand J-L (2014) Quantifying responses of crop species to $\mathrm{N}$ nutrition deficiency: improving $\mathrm{N}$ use efficiency. In: Sadras VO, Calderini DF (eds) Crop physiology: applications for genetic improvement and agronomy. Elsevier, Amsterdam, pp 161-206

Lemaire G, Gastal F (1997) N uptake and distribution in plant canopies. In: Lemaire $G$ (ed) Diagnosis on the nitrogen status in crops. Springer-Verlag, Heidelberg (Allemagne), pp 3-43

Lemaire G, Jeuffroy MH, Gastal F (2008) Diagnostic tools for crop and plant $\mathrm{N}$ status in vegetative stage. Theory and practices for crop $\mathrm{N}$ management. Eur J Agron 28:614-624 